\title{
Interpretive Structural Modeling of the Prospects of Ict Enabled Process Control in the Industry.
}

\author{
Jayalakshmi. ${ }^{1}$ and Pramod.V.R ${ }^{2}$ \\ ${ }^{I}$ Research scholar, Mechanical Department, Karpagam University, Coimbatore, Tamil Nadu, India. (Associate \\ Professor, Instrumentation and Control Engineering Dept, NSS College of Engineering, Palakkad, Kerala, \\ India \\ .$^{2}$ Associate Professor,Department of Mechanical Engineering,NSS College of Engineering,Palakkad-8, Kerala, \\ India.
}

\begin{abstract}
Optimization of process control systems is achieved by selection of appropriate control valves of various designs and functions. Information and communication technology (ICT) can be used for the purpose of enhancing the effectiveness of a system that operates in multi-favor locations and instruments. Wireless technologies for closed loop control systems are not yet implemented in industries. In this paper authors make an attempt to analyze the feasibility of implementing ICT enabled control system in industries. The properties of ICT enabled process control systems can be analyzed and their correlations can be established effectively by ISM (Interpretive Structural Modeling).This paper makes an attempt to unfold ISM using structural selfinteraction matrix, Initial reach ability matrix, and final reach ability matrix. A diagraph is prepared and converted to ISM as the second phase of this research.
\end{abstract}

Keywords: ICT, ISM, Structural self-interaction matrix, Initial reach ability matrix, final reach ability matrix.

\section{Introduction}

Many dimensions of expected benefits exist in the ICT technology adoption [1]. In education, different types of teaching and learning activities can be implemented using ICT. Recent trends in education are to implement a variety of educational programmes using ICT [2] .

A Plethora of research can be witnessed in internet based control systems concerning the use of protocols that access data wirelessly from a remotely located process. Such systems are observed and controlled by using Wireless and Internet communications technologies [3]. The design methodologies for the local computer-based control system do not consider the Internet environment issues like Web-based delay, Web-based safety, Web-based interface, and uncertain users. So they are not at all suitable for Internet-based control system.

Dealing with Internet time delay, hacking and data loss are the major problems faced by Internet based process control systems. A number of studies have been conducted worldwide regarding this issue; and the conclusion is that two compensators located in the feedback and feed forward paths in the architecture can efficiently deal with the Internet time delay and data loss, but the time delay and data loss in the feed forward channel prove to be more inhibitory influence on the control performance and is more difficult to be compensated [4].ICT is one of the advanced technologies that can be used for remote controlling in the process industry. With the advancements intelecommunications (telephone lines and wireless signals) in the modern era, information technology is accentuated by information and communication technology. ICT is comprised of computerand network hardware along with necessary software, which is nourished with IT, telephony, broadcast media, and all types of audio and video processing and transmission.In the process industries, specification of control valve performance is very important [5]. Both the valve lift and valve timing were controlled directly by electric motors in a typical engine valve control system [6]. Today, ICT has proved to be a potent technology for distributed and collaborative work. Thus, it is capable enough to be used in the high-level control of process plants.

The advantages of ICT include remote monitoring, adjustment of plant, easiness in collaboration between skilled plant managers in diverse locations and facility to change the physical location of plant management staff in response to business needs effortlessly.

Only a few researches were been done in emerging systematic design methods using this technology or in designing ICT enabled process control systems. ICT is now a well established technology in the modern competitive industrial world, but it's only a prelude. The best is yet to come. A wide variety of necessities for information are there in each process. While senior managers need information to help with their new ideas, middle management urges for detailed information to control process activities. People who work in operations need information to help them carry out their duties. Consequently, there is a need for many "information systems" in service at the same time.

This paper aims to analyze the feasibility of implementing ICT enabled process control systems in 
industry. The main objective here is to analyze the inter relationships between the prospects of ICT enabled process control systems using Interpretive Structural Modeling (ISM)

\section{Interpretive Structural Modeling (ISM) Methodology}

ISM is an ideal methodology to assess the interrelationships among the elements and their degree of associations. Management research is nurtured with a plethora of wide-ranging application of ISM [7]. The ISM methodology is interpretive as it is roiled from the synergic estimation of the group of experts. Based on relationship, an overall structure is hauling out from the complex set of variables [8; 9; 10]. ISM helped a lot to grow and survive the educational system in the rapidly fluctuating environment.[11].To work out the aims and objectives of this work, discussion was arranged with about 30 experts from industry having in-depth knowledge and high capability in the field and their ideas about implementing ICT enabled process control systems have been collected. The prospects ofICT enabled process control systems have been inter related using ISM where ISM is a strong tool to determine the inter connections. For this structural self-interaction matrix, initial reach ability matrix, final reach ability matrix and diagraph have been made and diagraph is converted to ISM. "Fig1" shows the schematic diagram of the study.

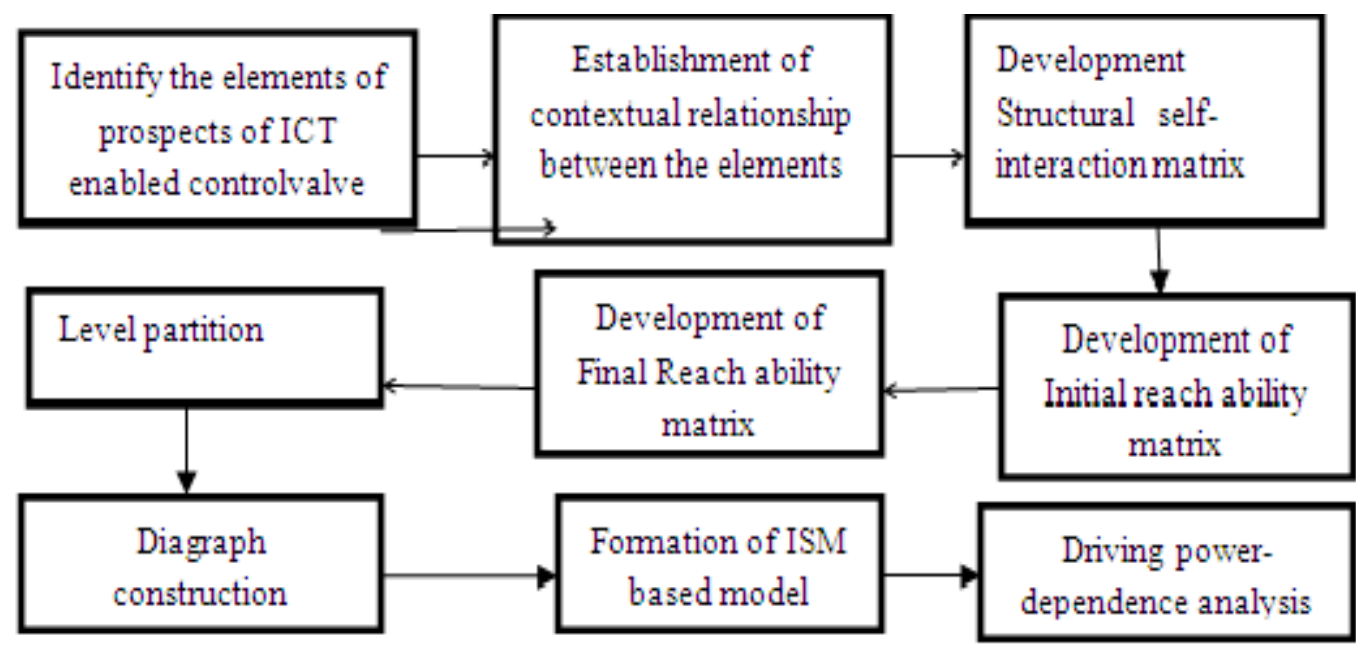

Figure1.Schematic diagram of the study

2.1. Prospects of ICT enabled process control systems.

At the outset, by discussing with about 30 experts from industry having good knowledge in ICT and closed loop control, prospects of ICT enabled process control systems were identified. These were further confirmed with three experts from Academia. From these well planned discussions prospects of ICT enabled control systems are found to be

- Highly innovative.

- A new area, where much possibility of research could be done.

- Only one control room is required to send signals to various control systems in theworld.

- For safety, secret codes can be used for operation so that only a particular group can operate the system.

- Usage of so many instruments can be avoided by using ICT, thereby reducing the cost.

- More opportunities for programmers.

- Robust and reliable technology.

- Profit margins will be high and

- $\quad$ End users respond to new ideas.

\subsection{Formation of the Structural self-interaction matrix (SSIM)}

SSIM shows the direction of contextual relationships among the elements. The enablers are shown in column one and these enablers are arranged in reverse order in other columns. ISM commences with the preparation of a SSIM, which shows the direction of contextual relationships among the elements of prospects points of ICT enabled control system. SSIM thus developed is shown in Table 1. 
Table 1. Structural self-interaction matrix of ICT process control system.

\begin{tabular}{|c|c|c|c|c|c|c|c|c|c|}
\hline & 9 & 8 & 7 & 6 & 5 & 4 & 3 & 2 & 1 \\
\hline 1 & $\mathrm{~A}$ & $\mathrm{~A}$ & $\mathrm{X}$ & $\mathrm{O}$ & $\mathrm{A}$ & $\mathrm{O}$ & $\mathrm{O}$ & $\mathrm{A}$ & 1 \\
\hline 2 & $\mathrm{O}$ & $\mathrm{O}$ & $\mathrm{O}$ & $\mathrm{O}$ & $\mathrm{A}$ & $\mathrm{O}$ & $\mathrm{O}$ & 1 & \\
\hline 3 & $\mathrm{O}$ & $\mathrm{O}$ & $\mathrm{O}$ & $\mathrm{O}$ & $\mathrm{O}$ & $\mathrm{V}$ & 1 & & \\
\hline 4 & $\mathrm{O}$ & $\mathrm{O}$ & $\mathrm{O}$ & $\mathrm{O}$ & $\mathrm{O}$ & 1 & & & \\
\hline 5 & $\mathrm{~A}$ & $\mathrm{X}$ & $\mathrm{A}$ & $\mathrm{O}$ & 1 & & & & \\
\hline 6 & $\mathrm{O}$ & $\mathrm{A}$ & $\mathrm{A}$ & 1 & & & & & \\
\hline 7 & $\mathrm{X}$ & $\mathrm{A}$ & 1 & & & & & & \\
\hline 8 & $\mathrm{O}$ & 1 & & & & & & & \\
\hline 9 & 1 & & & & & & & & \\
\hline
\end{tabular}

\subsection{Initial reachability matrix (IRM)}

In this step SSIM of above table has been converted into a matrix of binary elements named

as IRM. In this regard following rules are used 1) If the (imp) entry in the SSIM is V then substitute in the (I,j) entry in the reach ability matrix as 1 and (j,i) entry as $0 .(2)$ If the (i,j) entry in the SSIM is A, then substitute in the (i,j) entry in the reach ability matrix as 0 and (j,i) entry as 1 .(3) If the (i,j) entry in the SSIM is $\mathrm{X}$ then substitute in the (i,j) entry in the reach ability matrix as 1 and (j,i) entry as 1.(4) If the (i,j) entry in the SSIM is $\mathrm{O}$ then substitute in the (i,j) entry in the reach ability matrix as 0 and (j,i) entry as 0 . IRM thus developed is shown in Table 2.

Table 2. Initial reachability matrix of ICT process control system.

\begin{tabular}{|c|c|c|c|c|c|c|c|c|c|}
\hline Enablers & 1 & 2 & 3 & 4 & 5 & 6 & 7 & 8 & 9 \\
\hline 1 & 1 & 0 & 0 & 0 & 0 & 0 & 1 & 0 & 0 \\
\hline 2 & 1 & 1 & 0 & 0 & 0 & 0 & 0 & 0 & 0 \\
\hline 3 & 0 & 0 & 1 & 1 & 0 & 0 & 0 & 0 & 0 \\
\hline 4 & 0 & 0 & 0 & 1 & 0 & 0 & 0 & 0 & 0 \\
\hline 5 & 1 & 0 & 0 & 0 & 1 & 0 & 0 & 1 & 0 \\
\hline 6 & 0 & 0 & 0 & 0 & 0 & 1 & 0 & 0 & 0 \\
\hline 7 & 1 & 0 & 0 & 0 & 1 & 1 & 1 & 0 & 1 \\
\hline 8 & 1 & 0 & 0 & 0 & 1 & 1 & 1 & 1 & 0 \\
\hline 9 & 1 & 0 & 0 & 0 & 1 & 0 & 1 & 0 & 1 \\
\hline
\end{tabular}

2.4 Final reach ability matrix.

Here when establishing the relationship between various enablers transitivity was also considered. As per the rule of transitivity, if a variable A leads to a variable B and if $B$ leads to another variable $C$, then $A$ leads to $C$. Following this rule a final reachability matrix was developed and driving power and dependence of enablers are also computed. Driving power is the total number of ones in the corresponding rows and dependence is the total number of ones in the corresponding columns of final reach ability matrix. Final reach ability matrix is shown in table 3. 
Table 3_Final reachability matrix of ICT enabled process control system.

\begin{tabular}{|l|l|l|l|l|l|l|l|l|l|l|}
\hline Enablers & 1 & 2 & 3 & 4 & 5 & 6 & 7 & 8 & 9 & $\begin{array}{l}\text { Driving } \\
\text { power }\end{array}$ \\
\hline 1 & 1 & 0 & 0 & 0 & 1 & 1 & 1 & 0 & 1 & 5 \\
\hline 2 & 1 & 1 & 0 & 0 & 0 & 0 & 1 & 0 & 3 & 3 \\
\hline 3 & 0 & 0 & 1 & 1 & 0 & 0 & 0 & 0 & 0 & 2 \\
\hline 4 & 0 & 0 & 0 & 1 & 0 & 0 & 0 & 0 & 0 & 1 \\
\hline 5 & 1 & 0 & 0 & 1 & 1 & 1 & 1 & 1 & 1 & 6 \\
\hline 6 & 0 & 0 & 0 & 0 & 0 & 1 & 0 & 0 & 0 & 1 \\
\hline 7 & 1 & 0 & 0 & 1 & 1 & 1 & 1 & 1 & 1 & 6 \\
\hline 8 & 1 & 0 & 0 & 0 & 1 & 1 & 1 & 1 & 1 & 6 \\
\hline 9 & 1 & 0 & 0 & 0 & 1 & 1 & 1 & 1 & 1 & 6 \\
\hline $\begin{array}{l}\text { Depende } \\
\text { nce }\end{array}$ & 5 & 1 & 1 & 1 & 5 & 6 & 6 & 4 & 5 & \\
\hline
\end{tabular}

Level partition.

From the final reachability matrix, the reachability and antecedents of each element of prospects were developed.Then Level partition comes. This will help to categorize the equally valued elements of prospects. To get level partitions five iterations are necessitated. In the iterations, enablers are the elements themselves. Reachability set consists of a group of elements itself and other elements, which it may help to realize, whereas, the antecedent set consists of a group of element itself and other elements, which may help achieving it.The elements which are common in reachability sets and antecedent leads are assigned at the intersection set. The reachability sets, the intersection sets and antecedent sets help to pinpoint the top levelelements.If all the elements of the intersection set and reachability sets of a particular enable raresame, then that enabler is assigned in the top level group (level I group). The top level elements in the iteration I are removed from the set for the formation of the next table. This process is repeated till all levels of each element are found. These levels recognized by this procedure are exploited for the formation of diagraph. These subsequent iterations are shown in tables 4 to 6 .

Table 4 Iteration I

\begin{tabular}{|l|l|l|l|l|}
\hline Enablers & Reach ability set & Antecedent set & Intersection set & Level \\
\hline 1 & $1,5,6,7,9$ & $1,2,5,7,8,9$ & $1,5,7,9$ & \\
\hline 2 & $1,2,7$ & 2 & 2 & \\
\hline 3 & 3,4 & 3 & 3 & \\
\hline 4 & 4 & 4 & 4 & I \\
\hline 5 & $1,5,6,7,8,9$ & $1,5,7,8,9$ & $1,5,7,8,9$ & \\
\hline 6 & 6 & $1,5,6,7,8,9$ & 6 & I \\
\hline 7 & $1,5,6,7,8,9$ & $1,2,5,7,8,9$ & $1,5,7,8,9$ & \\
\hline 8 & $1,5,6,7,8,9$ & $5,7,8,9$ & $5,7,8,9$ & \\
\hline 9 & $1,5,6,7,8,9$ & $1,5,7,8,9$ & $1,5,6,7,8,9$ & \\
\hline
\end{tabular}

Table 5 Iteration II

\begin{tabular}{|l|l|l|l|l|}
\hline Enablers & Reach ability set & Antecedent set & Intersection set & Level \\
\hline 1 & $1,5,7,9$ & $1,2,5,7,8,9$ & $1,5,7,9$ & II \\
\hline 2 & $1,2,7$ & 2 & 2 & \\
\hline 3 & 3 & 3 & 3 & II \\
\hline 5 & $1,5,7,8,9$ & $1,5,7,8,9$ & $1,5,7,8,9$ & II \\
\hline
\end{tabular}


Interpretive Structural Modeling of the Prospects of Ict Enabled Process Control in the Industry.

\begin{tabular}{|l|l|l|l|l|}
\hline 7 & $1,5,7,8,9$ & $1,2,5,7,8,9$ & $1,5,7,8,9$ & II \\
\hline 8 & $1,5,7,8,9$ & $5,7,8,9$ & $5,7,8,9$ & \\
\hline 9 & $1,5,7,9$ & $1,5,7,9$ & $1,5,7,9$ & II \\
\hline
\end{tabular}

Table 6 Iteration III

\begin{tabular}{|l|l|l|l|l|}
\hline Enablers & Reach ability set & Antecedent set & Intersection set & Level \\
\hline 2 & 2 & 2 & 2 & III \\
\hline 8 & 8 & 8 & 8 & III \\
\hline
\end{tabular}

\subsection{Diagraph of opportunities.}

Diagraph simply signifies the relationship between the elements of prospects as per the numbers assigned to them. If there is a relationship between elements $j$ and $i$, this is represented by an arrow which points from $\mathrm{i}$ to $\mathrm{j}$. Diagraph of opportunities is shown in figure 2 .

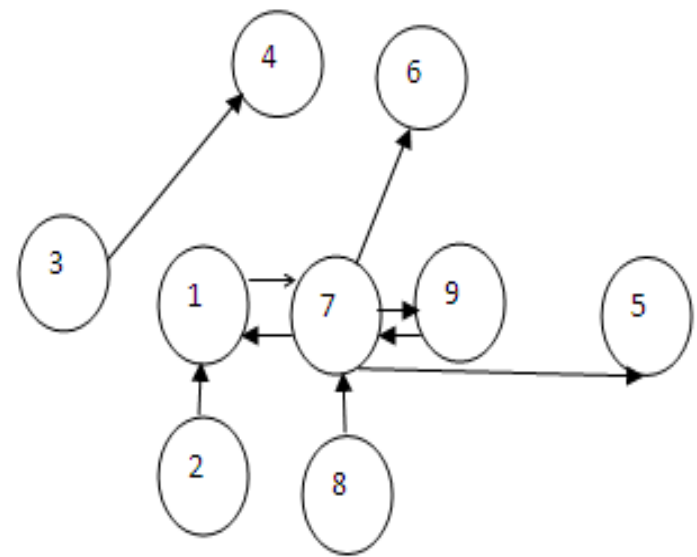

\subsection{ISM of Prospects of ICT enabled control valve}

Diagraph does not give a wide-ranging picture of the context. Diagraph is converted to ISM to get a complete representation of the inter relationship among the elements. In the ISM elements of prospects of control system are represented by names of elements itself and not by numbers and is shown in "Fig" 3 .

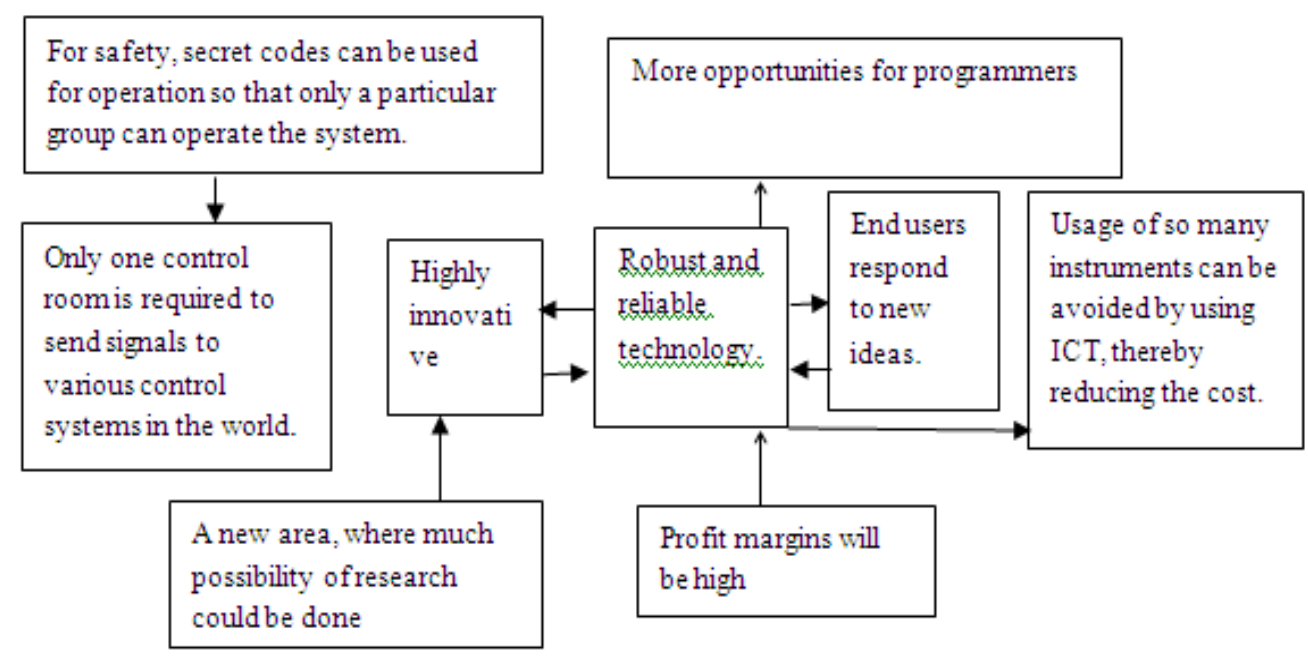

Figure 3. ISM of Prospects of ICT enabled control valve 


\subsection{Driving power-dependence diagram for opportunities of ICT enabled process control system.}

Based on the driving power and dependence, a graph is plotted as shown in the graph, classifying the enablers into four clusters. They are (i)Autonomous. (ii) Dependent (iii)linkage and (iv) independent enablers. Autonomous group has low driving power and low dependence.They can be eliminated from the system. Dependentgroup has low driving power and high dependence. Linkage group has high driving power and high dependence. They are the most important elements. Any action on this will affect the entire system.Independent group has high driving power and low dependence. Driving power-dependence diagram for opportunities of ICT enabled process controlsystem is shown in graph 1.

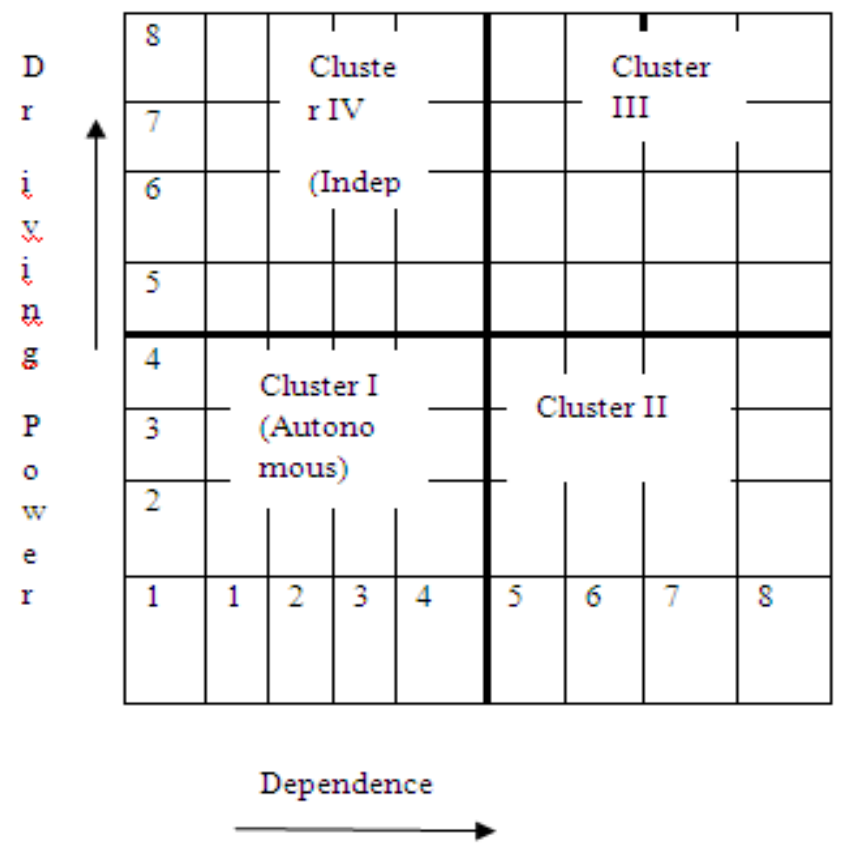

Graph 1

\subsection{Action plan based on study}

Linkage group has high driving power and high dependence and is the most important elements. By discussing with three industrial experts in the GM level andtwo experts from academia, an action plan has been formulated for enhancing the elements.

\section{Results And Discussions}

ICT enabled process control systemis a highly innovative new field with a great much scope for research.Profit margins will be high if ICT is used. It can be usedin many places like electricity office and water authority to note the consumption. For safe operation of the system, secret codes can be used for operation so that only a particular group can operate the system.In this case, only one control room is required to send signals to various control valves in the world. Implementation of the ICT process control systemsdecreases the usage of so many instruments in the process, thereby dropping off the cost.

\section{Conclusion.}

This paper illustrates the inter - relationships between the prospects of ICT process control systems using Interpretive Structural Modeling (ISM).An easier and commonly adopted practice to study the behavior of a system is to develop a standard model. This gave rise to the materialization of innumerable models in engineering and management. However these models usually have many limitations, the real-world applicability and heftiness of these models always supersedes. In the present work nine prospectsof ICT process control systemswere identified and considered for analysis. The identification of these points and awareness of their driving power and dependence helps the experts in industry to focus on them and prioritize them as tactical issues. The analysis can further be extended for intimidations of ICT enabled process controlsystems which are under progress. 


\section{Reference}

[1] Heinz Hollenstein, Determinants of the adoption of ICT: An empirical analysis based on firm-level data for the Swiss business sector, Structural Change and Economic Dynamics, Volume 15, Issue 3, 2004, Pages 315-342.

[2] Shabnam Bidarian, soheila Bidarian, Amirhosein Mohammad Davoudi; A Model for application of ICT in the process of teaching and learning, Procedia - Social and behavioral Sciences, Volume 29, 2011, Pages 1032-1041.

[3] Haydn A Thompson, Wireless and Internet communications technologies for monitoring and control, Control Engineering Practice, Volume 12, Issue 6, June 2004, Pages 781-791.

[4] S.H. Yang, X. Chen, L.S. Tan and L. Yang, Time delay and data loss compensation for Internet-based process control systems, Transactions of the Institute of Measurement and Control 27, 2 (2005) pp. 103_118

[5] Mark T. Coughran, Measuring the installed dead band of control valves, ISA Transactions, Volume 37, Issue 3, July 1998, Pages 147-154.

[6] Kosuke Nagaya, Hiroyuki Kobayashi and Kazuya Koike : Valve timing and valve lift control mechanism for engines, Mechatronics ,vol16, issue2, march2006, pages121-129.

[7] Thakkar.J, Deshmugh,S.G. Gupta A.D and Shankar.R, An integrated approach of Interpretive structural modeling and analytic network process., International journal of productivity and Performance management, vol.56, no: 1, ., 2007, pp.25-59.

[8] Mandal.A. and Deshmukh.S.G.() 'Vendor selection using interpretive structural modeling(ISM)', International journal of Operations and production management,vol14,no:6, 1994,pp.52-59.

[9] Warfield,J.N,; A Science of Generic design: Managing complexity through systems design, Iowa state university press, 1974,Ames, I.A.

[10] Faizal,M.N; Banwet.D.K and Shankar.R,"Supply chain risk mitigation: modeling the enablers “,Business process Management Journal, Vol 12,no:4, 2006, pp.535-552.

[11] Neena Sohani,, Nagendra Sohani; Developing Interpretive Structural Model for Quality Framework in Higher Education: Indian Context; Journal of Engineering Science \& Management Education; Vol-5 Issue-II (495-501); 2012 